\title{
Guía de aborto terapéutico en el Perú: ¿considera la objeción de conciencia médica?
}

\author{
Guideline on therapeutic abortion in Peru: does it consider medical \\ conscience objection?
}

\author{
Brian Montenegro-Díaz ${ }^{1, a}$, Rosita Tafur-Ramírez ${ }^{1, a}$, Antero Yacarini-Martínez ${ }^{1,2, b}$ \\ ${ }^{1}$ Escuela de Medicina Humana, Universidad Católica Santo Toribio de Mogrovejo, Lambayeque, Perú. \\ ${ }^{2}$ Área de Bioética Escuela de Medicina. Departamento Ciencias de la Salud. \\ ${ }^{a}$ Estudiante de Medicina de $6^{\circ}$ año; ${ }^{b}$ Biólogo-Microbiólogo.
}

An Fac med. 2015;76(1):77-8 / doi:10.15381/anales.v7611.11079

\section{Señor Editor:}

El fin de las profesiones sanitarias, históricamente amparado por el Derecho y tradicionalmente reconocido por la deontología profesional, ha sido siempre la defensa de la vida y la promoción de la salud - por otro lado, derechos básicos de la persona ${ }^{(1)}$. Debido a ello, imponer la obligación general a un médico en la participación de abortos terapéuticos puede calificarse, en principio, como un atentado al sentido último de la profesión e incluso, a la dignidad personal y al libre desarrollo de la personalidad, al ser la medicina una vocación comprometida, humana y profesionalmente, con la defensa de la vida humana.

El 27 de junio del 2014, en el Perú se aprobó la "Guía Técnica Nacional para la estandarización del procedimiento de la Atención Integral de la gestante en la Interrupción Voluntaria por Indicación Terapéutica del Embarazo menor de 22 semanas con consentimiento informado en el marco de lo dispuesto en el artículo 119º del Código Penal" (2).

En el contexto de esta guía se toma en cuenta las indicaciones médicas necesarias para la interrupción voluntaria del embarazo menor a 22 semanas que pongan en riesgo la vida de la madre; además se menciona el proceso a seguir para la ejecución del mismo. Sin embargo, no se menciona explícitamente un aspecto importante como es la objeción de conciencia del médico tratante.

Se define como objeción de conciencia a la "resistencia que el individuo ofrece al cumplimiento de una norma cuando entra en conflicto con sus propias convicciones" ${ }^{(3)}$.

Se puede entender que cuando se apela a la objeción de conciencia se está demandando que el principio de autonomía del profesional sea respetado, desde un plano de igualdad con respecto a la autonomía del paciente; sin embargo, no se puede apoyar en el principio de beneficencia, ya que este exigiría una conducta activa en beneficio de una persona. Frente a esto, se podría responder que el principio realmente aplicable sería el de no maleficencia, ya que la objeción de conciencia implica omisión de un comportamiento que podría resultar lesivo para un sujeto ${ }^{(1)}$.

La constitución política del Perú, en el Artículo 2o señala que: "toda persona tiene derecho a la libertad de conciencia y de religión, en forma individual o asociada. No hay persecución por razón de ideas o creencias. No hay delito de opinión. El ejercicio público de todas las confesiones es libre, siempre que no ofenda la moral ni altere el orden público" (4).

En nuestro país no existe un reconocimiento legal expreso de la objeción de conciencia de los profesionales con respecto al aborto. Esta carencia ha sido suplida por pronunciamientos constitucionales en países como España, Italia, Francia, entre otros, para salvaguardar la conciencia de los sanitarios que no quisieran colaborar en dichos actos ${ }^{(1)}$. Esta medida no ha sido contemplada en la guía técnica nacional.

Finalmente, en el Perú existe un gran vacío legal en lo que refiere a la objeción de conciencia de los profesionales hacia el aborto, dejando desprotegido al médico desde el punto de vista profesional por una posible discriminación en su entorno, además de posibles problemas legales con el paciente al incumplir una indicación que genere riesgo para la gestante. Se propone se realicen pronunciamientos constitucionales a favor de la objeción de conciencia médica en contra del aborto terapéutico en el Perú. 


\section{REFERENCIAS BIBLIOGRÁFICAS}

1. Aparisi MA, López GJ. El derecho a la objeción de conciencia en el supuesto del aborto. De la fundamentación filosófico-jurídica a su reconocimiento legal. Persona y Bioética. 2006;10(26):35-41.

2. Ministerio de Salud. Guia Técnica Nacional para la estandarización del procedimiento de la Atención Integral de la gestante en la Interrupción Voluntaria por Indicación Terapéutica del Embarazo menor de 22 semanas con consentimiento informado en el marco de lo dispuesto en el artículo $119^{\circ}$ del Código Penal". Diario El Peruano. 2014;20(2):526379526387.

3. López GJ. Objeción de Conciencia Farmacéutica. Cuadernos de Bioética. 1997;8(30):846-74.

4. Constitución Política del Perú. Derechos Fundamentales de la Persona. 1993.
Carta recibida el 11 de noviembre de 2014

Conflicto de intereses: Los autores declaran no existir conflicto de intereses.

Correspondencia:

Brian Montenegro-Díaz

Correo electrónico: brian_mondi@hotmail.com 